\title{
CHROMATOGRAPHIC BEHAVIOR OF BORNYL ACETATE DIASTEREOMERS UNDER THE CONDITIONS OF REVERSED-PHASE HIGH-PERFORMANCE LIQUID CHROMATOGRAPHY (HPLC)
}

\author{
Larisa V. Sotnikovaa, ${ }^{a}$, Polina V. Goryunova ${ }^{a}$, Sergey A. Sozinova,b, and Natal'ya V. Ivanovab \\ ${ }^{\text {a }}$ Kemerovo Multi-Access Center of the Federal Research Centre \\ of Coal and Coal Chemistry of the Siberian Branch of the Russian Academy of Sciences, \\ Rukavishnikova Str. 21, Kemerovo, 650025, Russian Federation \\ ${ }^{\mathrm{b}}$ Kemerovo State University, \\ Krasnaya Str. 6, Kemerovo, 650043, Russian Federation \\ * e-mail: lorikkemerovo@gmail.com
}

Received October 24, 2017;

Accepted in revised form November 26, 2017;

Published December 30, 2017

\begin{abstract}
The present paper illustrates the results of the study on chromatographic behavior and optimization of some parameters of the method of quantitative determination of bornyl acetate and isobornyl acetate diastereomers under the conditions of reversed-phase highperformance liquid chromatography. Chromatography was performed with HPLC platform Agilent 1200 with diode-matrix detector and a column Agilent Zorbax XDB, Extend-C18. Detection of the studied analytes was performed at a wavelength of $210 \mathrm{~nm}$. Determinationof the concentration of bornyl acetate isomers was carried out in mixture with other components of the Abiessibirica essential oil in chromatographic systems with mobile phases of acetonitrile-water or isopropyl alcohol-water. The range of analyte concentrations in a sample was varied from 2 to $430 \mathrm{mg} / \mathrm{ml}$ for bornyl acetate and from 2 to $950 \mathrm{mg} / \mathrm{ml}$ for isobornyl acetate. It is stated that in a chromatographic system with a mobile phase, based on acetonitrile, the peaks of the studied components have an asymmetric shape, and the retention times of analytes increase with the decrease of their concentrations in a sample. In a chromatographic system with isopropyl alcohol the asymmetry of the bornyl acetate peak disappears, the width decreases and the retention time stabilizes. For isobornyl acetate a peak width also decreases, its asymmetry is preserved, but at the same time, the asymmetry coefficient takes on permitted values (less than 2). Calibration charts for the mentioned compounds in the used eluents are linear throughout the studied concentration range with correlation coefficients of $\mathrm{R}^{2}>0.998$. Thus, the conducted researches allow to recommend the reversed-phase HPLC variant for the separate quantitative determination of bornyl acetate and isobornyl acetate in the pine oil samples.
\end{abstract}

Keywords: High-performance liquid chromatography, bornyl acetate, isobornyl acetate, Abiessibirica essential oil.

DOI 10.21603/2500-1418-2017-2-2-44-48

\section{INTRODUCTION}

A distinctive feature of the natural biosynthetic reactions is a formation of only one of the possible structural isomers of the substance. Therefore, generally, isomers of only one spatial structure are present in the products, made out of natural raw materials. The presence of several isomers in the product may be a characteristic of its chemical origin. The danger of using isomers, produced in the chemical synthesis, has not been proven for all substances, but there is information on the harmful effect of optical isomers of different biological and pharmacological action [1-3], therefore, the consumers, who impose increased requirements to the product quality, pay special attention to its natural origin. The research in this area is ongoing and currently, the relevant problem is the development of methods for recognition of counterfeit products, in particular, food $[4,5]$ and pharmaceutical products $[6,7]$, as well as perfumery. This task is difficult to solve using simple physical and chemical methods, without the stage of preliminary separation of the components. One of the most adequate methods for studying the compound and identifying the components of organic substances complex mixtures is the method of high performance liquid chromatography (HPLC). The advantage of this method lies in the possibility of separation and identification of a broad range of substances, including high-molecular compounds and compounds, characterized by chemical and thermal instability. Furthermore, the use of HPLC allows to solve the problem of the joint determination of spatial isomers of various substances with the use of special chromatography columns [8-11].

Recently, the interest increased in the production of Abiessibirica essential oil. Herewith, the range of the products, made out with the use of this oil, increased [12]. The value of pine oil is considerably determined by the content of a substance from the terpenoid class, ester borneol and acetic acid - bornyl acetate, due to its predominant use for obtaining medical camphor. Such terpenes as pinene and limonene, as well as sesquiterpenoids, are the raw material for perfume and chemical industries [13]. L-bornyl acetate, the main component of natural Abiessibirica essential oil, has a diastereomer of synthetic origin - isobornyl acetate.

Please cite this article in press as: Sotnikova L.V., Goryunova P.V., Sozinov S.A., and Ivanova N.V. Chromatographic behavior of bornyl acetate diastereomers under the conditions of reversed-phase HIGH-performance liquid chromatography (HPLC). Science Evolution, 2017, vol. 2, no. 2, pp. 44-48. DOI: 10.21603/2500-1418-2017-2-2-44-48.

Copyright (C) 2017, Sotnikova et al. This is an open access article distributed under the terms of the Creative Commons Attribution 4.0 International License (http:// creativecommons.org/licenses/by/4.0/), allowing third parties to copy and redistribute the material in any medium or format and to remix, transform, and build upon the material for any purpose, even commercially, provided the original work is properly cited and states its license. This article is published with open access at http:// scienceevolution.ru/. 


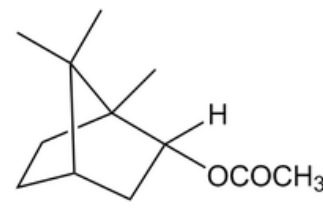

L-Bornyl Acetate

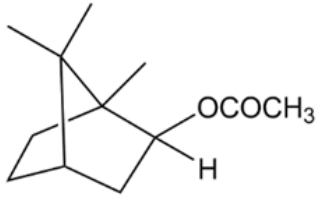

D-BornylAcetate (IsobornylAcetate)

Fig. 1. Structural formulae of bornyl acetate isomers.

To determine the quality of products, containing pine oil, and detect the facts of counterfeit by blending with synthetic isobornyl acetate, a promising method is HPLC in the reversed-phase variant of chromatography.

The HPLC distinctive feature is the dependence of the system chromatographic parameters not just on the sorbent type and brand, but sometimes even on the producer. Therefore, a typical practice of HPLC and other chromatographic methods is an objectively forced modification of the chromatography terms in compliance with the fitness requirements of the chromatographic system [14]. In literature there are no indications of the possibility to determine quantitatively bornyl acetate diastereomers with HPLC. Therefore, the present paper deals with the study of chromatographic behavior of bornyl acetate diastereomers under the conditions of reversed-phase HPLC, as well as with the development of the methods of their quantitative determination in the Abiessibirica essential oil.

\section{MATERIALS AND METHODS OF STUDY}

The research objects were bornyl acetate (BA) and isobornyl acetate (IBA). BA is the main component of the Abiessibirica essential oil, its mass concentration in a sample was determined with the method of gas chromatography-mass-spectrometry and was $42.7 \%$. IBA is the product of chemical synthesis with the component content of $95 \%$. A series of samples with BA content of $2-430 \mathrm{mg} / \mathrm{ml}$ and IBA content of $2-950 \mathrm{mg} / \mathrm{ml}$ was analyzed with the chromatographic platform Agilent 1200 with diode-matrix detector (DMD). The column was Agilent Zorbax Extend XDB-C18 with the size of $2.1 \times 150 \mathrm{~mm}$, the sorbent grain size was $5 \mu \mathrm{m}$, the bonded phase was dimethyloctadecylsilane. The mobile phase was acetonitrile (A) - water (B), the elution gradient mode of all the pine oil components was: $1700 \mu \mathrm{l} 60 \% \mathrm{~A} ; 2600$ $\mu \mathrm{l}$ from 80 to $90 \% \mathrm{~A} ; 3200 \mu \mathrm{l} 100 \% \mathrm{~A}$. The mobile phase flow rate was $100 \mu \mathrm{l} / \mathrm{min}$, the column temperature was $35^{\circ} \mathrm{C}$. The detection mode was performed at a wavelength of $210 \mathrm{~nm}$. The added sample volume was $5 \mu \mathrm{l}$. The mobile phase was isopropyl alcohol (A) - water (B), the isocratic mode was $1700 \mu 160 \% \mathrm{~A}$. The mobile phase flow rate was $100 \mu \mathrm{l} / \mathrm{min}$, the column temperature was $35^{\circ} \mathrm{C}$. The chromatogram processing was performed with ChemStation software.

\section{RESULTS AND DISCUSSION}

To select the conditions for the chromatographic separation of the main components of the Abiessibirica essential oil, a $16 \%$ - solution of pine oil in acetonitrile was used. The choice of the sample solvent is due to the fact that bornyl acetate is poorly soluble in acetonitrile aqueous solutions. At the chosen analyte concentration, there were no column overloading and detector in relation to the oil components, however, the asymmetric form of thepeak ofbornyl acetate indicates poor compatibility of this analyte with the used in the chromatographic system mobile phase. Abiessibirica essential oil chromatogram is indicated in fig. 2 .

Chromatography was performed in the gradient mode to achieve the best separation of the sample components. The indicated in fig. 2 data show that the $\mathrm{BA}$ retention time under these conditions is $12.06 \mathrm{~min}$. Despite the fact that BA is the main component of the essential oil, its peak intensity is low, which is due to low light absorptioncoefficient of acetate in the selected area of the UV-range $(\lambda=210 \mathrm{~nm})$. However, using a sensitive DMD, it is not an obstacle to determine quantitavelythe BA content with an acceptable measurement error.

Analysing the BA peak position on the chromatogram, you can see that the rest essential oil components elute much later, in the area of retention times greater than $20 \mathrm{~min}$, when acetonitrile concentration in the mobile phase reaches $60 \%$. Therefore, to determine quantitatively the BA content in the oil, isocratic elution with a mobile phase wasthen used with the mentioned acetonitrile content. After the main component elution, the remaining oil components were washed out with a $100 \%$-acetonitrile.

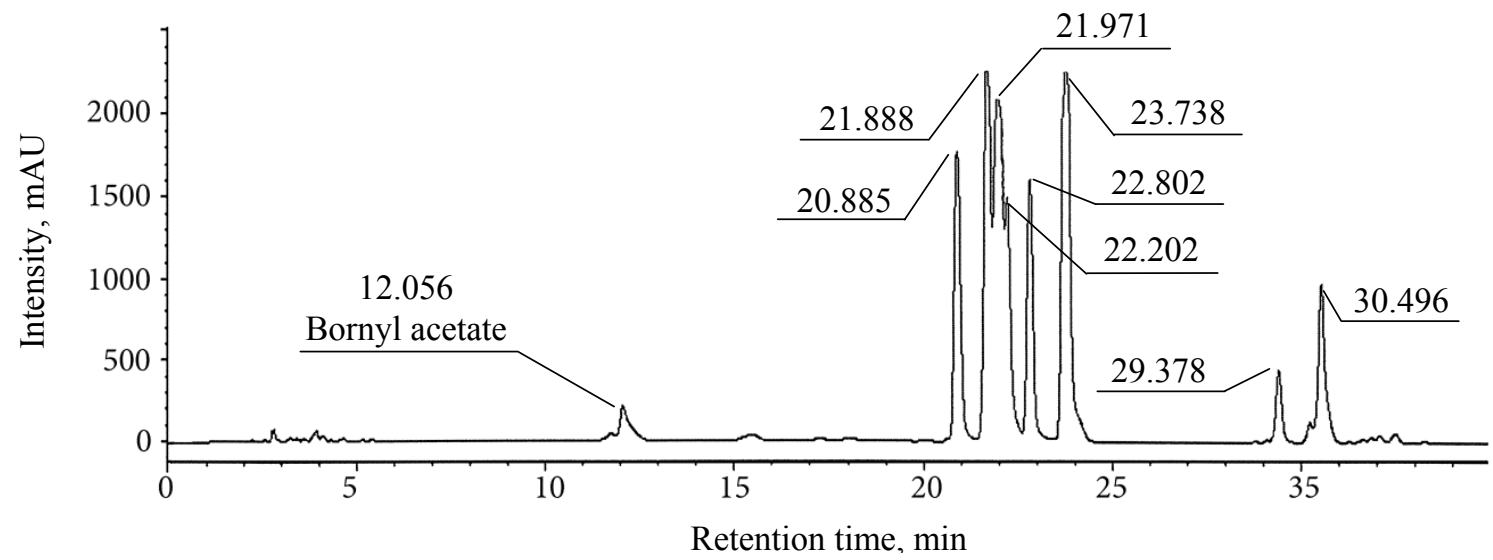

Fig. 2. Chromatogram ofAbiessibirica essential oil. Sample is a $16 \%$-solution of oil in acetonitrile. Mobile phase is acetonitrile(60\%)-water(40\%). The signal is registered at a wavelength of $\lambda=210 \mathrm{~nm}$. 


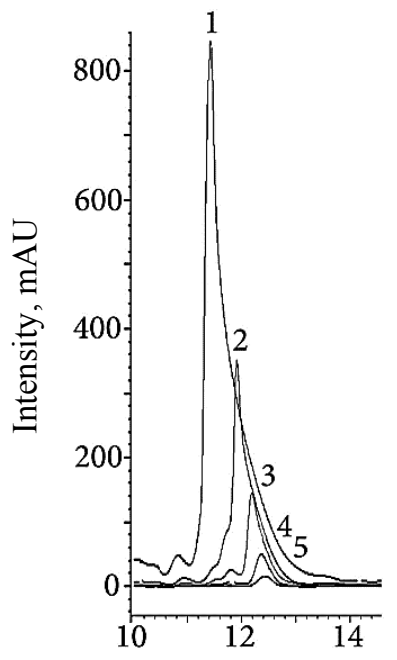

Retention time, min

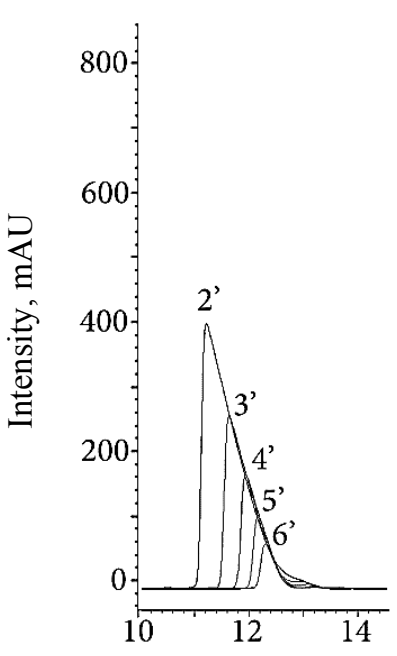

Retention time, $\min$

Fig. 3. Chromatogram sections with peaks of BA (a) and IBA (b) in acetonitrile chromatographic systems. Detection is at a wavelength of $\lambda=210 \mathrm{~nm}$. The figures on the chart correspond to different analyte amount, the respective values are indicated in table 1 .

To determine the range of the DMD linear response to the changing component concentration, the samples with BA content of $2-430 \mathrm{mg} / \mathrm{ml}$ were preparedwith the method of successive dilution from the oil sample with a known concentration of the component. At overlaying the sections of the chromatograms of the samples of essential oil of different concentration, fig. 3(a), we can see that the BA peak has an asymmetric form and the analyte retention time permanently increases with a decrease in its concentration in the sample. Table. 1 shows the retention times of $\mathrm{BA}$ with various concentrations in a sample and the calculated values of the peak asymmetry coefficient $A_{S}$.

Table 1. Chromatographic parameters of analyte peaks at usingacetonitrile eluent

\begin{tabular}{|c|c|c|c|c|c|}
\hline $\begin{array}{c}\text { Ser. } \\
\text { no. }\end{array}$ & $\begin{array}{c}\text { Analyte } \\
\text { quantity, } \\
\mu \mathrm{g}\end{array}$ & $\begin{array}{c}\text { Retention } \\
\text { time }\left(\mathrm{t}_{\mathrm{R}}\right), \\
\text { min. }\end{array}$ & $\begin{array}{c}\text { Peak } \\
\text { area, } \\
\text { p.u. }\end{array}$ & $\begin{array}{c}\text { Width, } \\
\mathrm{W}_{0.1}\end{array}$ & $\begin{array}{c}\text { Peak } \\
\text { asymmetry } \\
\text { coefficient, } \\
\mathrm{A}_{\mathrm{s}} .\end{array}$ \\
\hline \multicolumn{6}{|c|}{ bornyl acetate } \\
\hline 1 & 2.14 & 11.416 & 27470 & 1.42 & 2.1 \\
\hline 2 & 0.71 & 11.902 & 9266 & 1.25 & 1.4 \\
\hline 3 & 0.24 & 12.177 & 2945 & 0.63 & 2.2 \\
\hline 4 & 0.10 & 12.330 & 1788 & 0.45 & 1.4 \\
\hline 5 & 0.03 & 12.422 & 306.5 & 0.36 & 1.2 \\
\hline 6 & 0.01 & 12.519 & 96.3 & 0.32 & 1.0 \\
\hline \multicolumn{7}{|c|}{ isobornyl acetate } \\
\hline $1^{\prime}$ & 4.75 & 10.657 & 43164 & 1.61 & 7.5 \\
\hline $2^{\prime}$ & 2.38 & 11.353 & 20238 & 1.33 & 5.0 \\
\hline $3^{\prime}$ & 1.19 & 11.811 & 9479 & 1.06 & 3.0 \\
\hline $4^{\prime}$ & 0.60 & 12.142 & 5226 & 0.84 & 2.5 \\
\hline $5^{\prime}$ & 0.30 & 12.387 & 2631 & 0.73 & 2.0 \\
\hline $6^{\prime}$ & 0.15 & 12.539 & 1338 & 0.62 & 1.5 \\
\hline $7^{\prime}$ & 0.10 & 12.330 & 1188 & 0.55 & 1.3 \\
\hline $8^{\prime}$ & 0.04 & 12.422 & 306.5 & 0.53 & 1.2 \\
\hline $9^{\prime}$ & 0.01 & 12.519 & 96.3 & 0.50 & 1.2 \\
\hline
\end{tabular}

Similar studies were conducted for IBA. The difference consisted in the wider range of the studied analyte concentrations from 2 to $950 \mathrm{mg} / \mathrm{ml}$. The obtained data are indicated in fig. 3(b) and in table 1.

The presented figures show that the bornyl acetate diastereomer peaks in a chromatographic system with a mobile phase acetonitrile-water are characterized by a considerable asymmetry up to a concentration of analyte in a sample of $20 \mu \mathrm{g} / \mathrm{ml}$ for BA and $30 \mu \mathrm{g} / \mathrm{ml}$ for IBA. This fact is most pronounced in the chromatographic system with IBA. The occurrence of tailed peaks at a high concentrations of the studied components is due to the specificity of interaction of analytes with the mobile phase. During the simulation of a dilution of the pine oil sample with the mobile phase, emulsion was observed. Because of the desire to ensure homogeneity of the samples at their placement to the column, the samples were prepared with the use of a $100 \%$-acetonitrile. However, as it can be found from the obtained chromatograms, the mobile phase acetonitrile-water is not suitable for the studied analytes, especially when the concentration of these substances in a sample is more than $20 \mu \mathrm{g} / \mathrm{ml}$.

The correction of the eluent compound was carried out, aimed at eliminating the peak asymmetry of the studied analytes; the organic phase was replaced by isopropyl alcohol. At mixing the mobile phase, based on isopropyl alcohol and water, with IBA, no emulsionis observed; the sample is a molecular solution. The essential oil sample, when diluted by eluent, as before, represents the emulsion, however, suggesting a similar diastereomer behavior in the mobile phase, it can be assumed that the sample becomes homogeneous in relation to the determined component. Fig. 4 shows the chromatogram of the Abiessibirica essential oil in the eluent isopropyl alcohol-water.

Based on previously obtained data, the chromatography was performed in isocratic mode with the isopropyl alcohol content of $60 \%$. Indicated in fig. 4 data show that the bornyl acetate peak is not overlapped by the peaks of other oil components, absence of closely eluted connections is an advantage of the method offered. In fig. 5 you can see the changes in the BA and IBA chromatographic peaks in the isopropyl alcohol system depending on the analyte concentration.

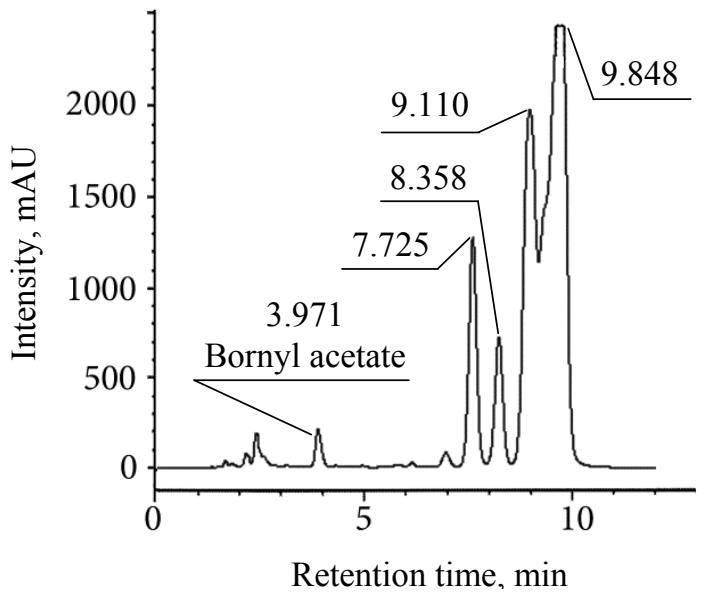

Fig. 4. Chromatogram ofAbiessibirica essential oil. Sample is a $12.5 \%$-solution of oil in isopropyl alcohol. Mobile phase is isopropyl alcohol (60\%)-water (40\%). The signal was registered at a wavelength of $\lambda=210 \mathrm{~nm}$. 


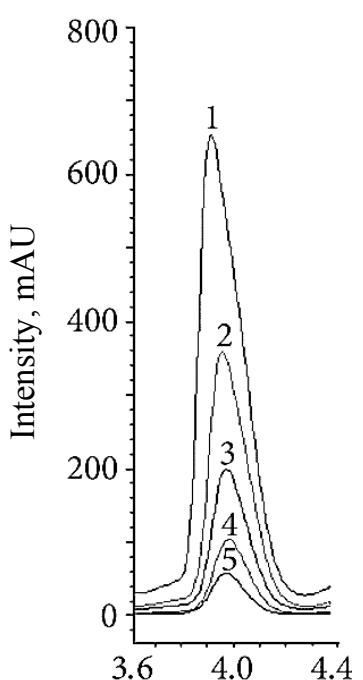

Retention time, $\min$

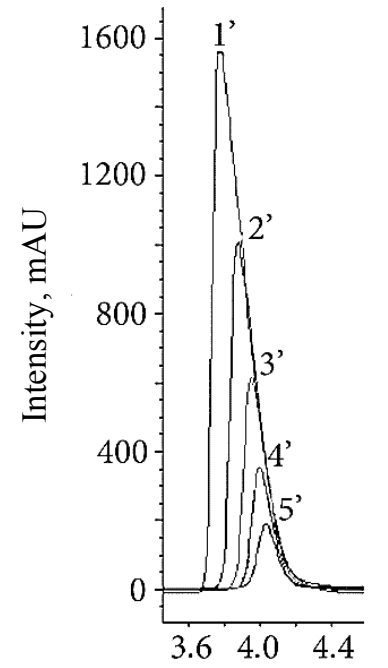

Retention time, $\min$

(b)
Fig. 5. Chromatogram sections with peaks of BA (a) and IBA (b) in isopropyl alcohol chromatographic systems. Detection is at a wavelength of $\lambda=210 \mathrm{~nm}$. The figures on the chart correspond to different analyte amount, the respective values are indicated in Table 2.

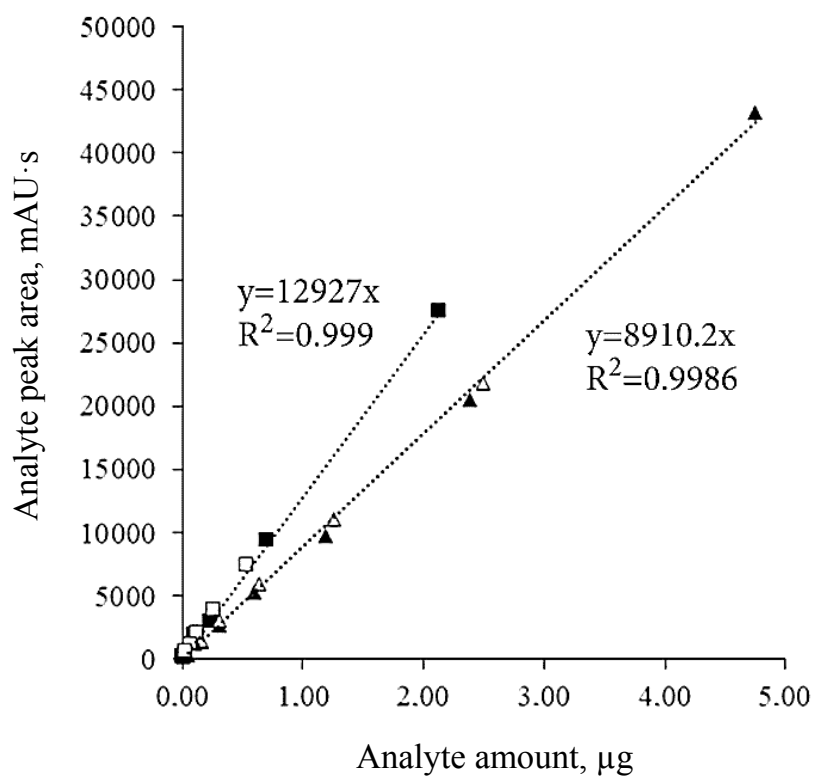

Fig.6. Calibration charts for bornyl acetate ( $\mathbf{a})$ and isobornyl acetate $(\boldsymbol{\Delta})$, obtained in eluentsacetonitrilewater (60:40) and isopropyl alcohol - water (60:40).

In the isopropyl alcohol chromatographic system, the BA peak asymmetry and width significantly decreased, and the retention time stabilized and was $3.96 \pm 0.01 \mathrm{~min}$. For IBA, there is also a decrease in these parameters, however, a change in retention time is still observed at the chromatography of the solutions with different concentration. The obtained under different elution conditions data were processed with linear regression analysis. Dependence of peak areas on their concentrations are indicated in Fig. 6.
Table 2. Chromatographic parameters of analyte peaks at using isopropyl alcohol eluent

\begin{tabular}{|c|c|c|c|c|c|}
\hline $\begin{array}{c}\text { Ser. } \\
\text { no. }\end{array}$ & $\begin{array}{c}\text { Analyte } \\
\text { quantity, } \\
\mu \mathrm{g}\end{array}$ & $\begin{array}{c}\text { Retention } \\
\text { time }\left(\mathrm{t}_{\mathrm{R}}\right), \\
\text { min. }\end{array}$ & $\begin{array}{c}\text { Peak } \\
\text { area, } \\
\mathrm{pu}\end{array}$ & $\begin{array}{c}\text { Width, } \\
\mathrm{W}_{0.1}\end{array}$ & $\begin{array}{c}\text { Peak } \\
\text { asymmetry } \\
\text { coefficient, } \\
\mathrm{A}_{\text {s. }}\end{array}$ \\
\hline \multicolumn{6}{|c|}{ bornyl acetate } \\
\hline 1 & 0.54 & 3.913 & 7333 & 0.36 & 2.0 \\
\hline 2 & 0.27 & 3.956 & 3766 & 0.33 & 1.3 \\
\hline 3 & 0.13 & 3.971 & 1919 & 0.24 & 1.3 \\
\hline 4 & 0.07 & 3.978 & 990 & 0.24 & 1.2 \\
\hline 5 & 0.04 & 3.970 & 539 & 0.25 & 1.1 \\
\hline \multicolumn{7}{|c|}{ isobornyl acetate } \\
\hline $1 '$ & 2.50 & 3.771 & 21832 & 0.5 & 3.3 \\
\hline 2 & 1.25 & 3.879 & 11021 & 0.35 & 1.7 \\
\hline 3 & 0.63 & 3.949 & 5853 & 0.28 & 1.5 \\
\hline 4 & 0.31 & 3.998 & 3017 & 0.25 & 1.5 \\
\hline 5 & 0.16 & 4.031 & 1504 & 0.24 & 1.0 \\
\hline
\end{tabular}

According to the obtained data, the changes in the chromatographic peak parameters of the analyzed compounds for the two types of the mobile phases do not lead to the violation of the calibration charts linearity over the whole studied analyte concentration range, which indicates a small dependence of the separation parameters on conditions, offered by the method, as well as a high stability of the obtained in the test results. The linearity criterion of the calibration charts for the analyte determination - the correlation coefficient - has high values of ${ }^{2}{ }_{B A}=0.9990$ and $R_{\text {IBA }}^{2}=0.9986$. The various slope of dependencies "signal - concentration" indicates that the interaction nature of the studied components with the column stationary phase is different, which may be a consequence of the sample matrix effect.

\section{CONCLUSIONS AND RECOMMENDATIONS}

Despite the fact that bornyl acetate and isobornyl acetate solutions have a low absorption coefficient in the UV range at $\lambda=210 \mathrm{~nm}$, the obtained in the present paper conditions for conducting the chromatographic analysis allow to use the reversed-phase HPLC for determination of the quantitative content of bornyl acetate diastereomers in the concentration range of 2-20-30 $\mu \mathrm{g} / \mathrm{ml}$ in the pine oil samples. To ensure homogeneity of the sample, added to the chromatographic system, it is preferable to use an isopropyl alcohol mobile phase. There is a possibility of identification of bornyl acetate isomers at the joint presence with HPLC, basing on the differences in the interaction nature of the studied components with the column stationary phase, as well as in the chromatographic peak form, however, this issue requires additional studies of mixtures with different content of the determined components.

The work is performed with the equipment of the Research and Analytical Centre of Studies of Carbonic Substance Chemical Compound and Structure (Kemerovo Multi-Access Center of the Federal Research Centre of Coal and Coal Chemistry of the Siberian Branch of the Russian Academy of Sciences). 


\section{REFERENCES}

1. Vasilenko I.A., Lebedeva M.V., and Listrov V.A. Opticheskie izomery v farmatsevtike [Optical isomers in pharmaceutical industry]. Razrabotka i registratsiya lekarstvennykh sredstv [Development and registration of medicines], 2015, no. 1, pp. 92-104.

2. Tjukavkina N.A. and Baukov Yu.I. Bioorganicheskaya khimiya[Bioorganic Chemistry]. Moscow: Drofa Publ., 2004. 544 p.

3. Mashkovskij M.D. Lekarstvennye sredstva [Pharmaceuticals]. $15^{\text {th }}$ edn. Moscow: Novaya Volna Publ., 2005. 1164 p.

4. GOST R 52100-2003. Spredy i smesi toplenye. Obshchie tekhnicheskie usloviya [State Standard R 52100-2003. Spreads and melted blends. General specifications]. Moscow: Standartinform Publ., 2008. 24 p.

5. GOST R 52677-2006. Masla rastitel'nye, zhiry zhivotnye i produkty i khpererabotki. Metody opredeleniya massovoi doli transizomerov zhirnykh kislot [State Standard R 52677-2006. Vegetable oils, animal fats and products of their processing. Methods of determining mass fraction of fatty acids trans-isomers]. Moscow: Standartinform Publ., 2014. 24 p.

6. Williams D.A. and Lemke T.L. Foye`s Principles of Medicinal Chemistry. Washington: Lippincott Williams \& Wilkins, 2005.346 p.

7. Lebedeva M.V. Makrotsiklicheskie antibiotiki kak novye khiral'nye selektory v nevodnom kapillyarnom elektroforeze. Avtoref. diss. kand. khim. nauk [Macrocyclic antibiotics as a new chiral selectors in nonaqueous capillary electrophoresis. Cand. chem. sci. thesis]. Moscow, 2014. 28 p.

8. Ariens E.J., Sojudin W., and Timmermans P. Stereochemistry and Biological Activity of Drugs. Oxford, 1983. 249 p.

9. Gyllenhaal O. and Lindner W.J. HPLC enantiomer separation of a chiral 1,4-dihydropyridine monocarboxylic acid. Pharm. Biomed. Anal., 2004, vol. 16, no. 35(2), pp. 259-266.

10. Chakravarthy V.K. and Shankar D.G. HPLC method for determination of LactosamideS(-)enantiomer in bulk and pharmaceutical formulation. RJCABP, 2011, no. 4, pp. 744-752.

11. Lacroix P.M., Dawson B.A., Sears R.W., and Black D.B. HPLC and NMR Methods for the Quantitation of the (R)-Enantiomer in (-)-(S)-Timolol Maleate Drug Raw Materials. Chirality, 1994, no. 6, pp. 484-491.

12. Tekhnicheskie usloviya. TU 10.89.19-001-2256258-2016. Voda pikhtovaya "PikhtopretBio" [Technical Specification 10.89.19-0012256258-2016. Pine water PikhtopretBio]. Kemerovo: Novye Resursy Publ., 2016. 17 p.

13. Tkachev A.V. and Khan V.A. Khvoinye derev'ya Sibirii Dal'nego Vostoka - istochniki seskviterpenoidov [Conifers of Siberia and Far East are a source of sesquiterpenoids]. Izv. SOANSSSR. Ser, khim. nayk [Bulletin of the Siberian Branch of the USSR Academy of Sciences. Aseriesofchemicalsciences], 1987, iss. 4, no. 2, pp. 95-104.

14. Epshtejn N.A. Otsenka prigodnosti (validatsiya) VEZhKh metodik v farmatsevticheskom analize (obzor) [The assessment of applicability (validation) of HPLC methods in pharmaceutical analysis (review)]. Khimiko-farmatsevticheskiy zhurnal [Chemicalpharmaceutical journal], 2004, vol. 38, pp. 40-56.

\section{Larisa V. Sotnikova}

Cand.Sci.(Chem.), Associate Professor, Research Officer, Kemerovo Multi-Access Centre of the Federal Research Centre of Coal and Coal Chemistry of the Siberian Branch of the Russian Academy of Sciences, Kemerovo, Russian Federation

\section{Polina V. Goryunova}

Cand.Sci.(Chem.), Research Officer, Kemerovo Multi-Access Centre of the Federal Research Centre of Coal and Coal Chemistry of the Siberian Branch of the Russian Academy of Sciences, Kemerovo, Russian Federation

\section{Sergey A. Sozinov}

Cand.Sci.(Physics and Mathematics), Chief Research Officer, Director, Kemerovo Multi-Access Centre of the Federal Research Centre of Coal and Coal Chemistry of the Siberian Branch of the Russian Academy of Sciences, Kemerovo, Russian Federation

\section{Natal'ya V. Ivanova}

Cand.Sci.(Chem.), Associate Professor of the Department of Analytical and Inorganic Chemistry, Fundumental Sciences Institution, Kemerovo State University, Kemerovo, Russian Federation 